\title{
Second-line chemotherapy for small-Cell Lung Cancer (SCLC).
}

$\operatorname{AUTHOR}(\mathrm{S})$ :

Kim, Young Hak; Mishima, Michiaki

CITATION:

Kim, Young Hak ... [et al]. Second-line chemotherapy for small-Cell Lung Cancer (SCLC).. Cancer treatment reviews 2011, 37(2): 143-150

ISSUE DATE:

2011-04

URL:

http://hdl.handle.net/2433/137220

\section{RIGHT:}

(C) 2010 Elsevier Ltd; この論文は出版社版でありません。引用の際には 出版社版をご確認ご利用ください。; This is not the published version. Please cite only the published version. 


\section{Second-line Chemotherapy for Small-Cell Lung Cancer (SCLC)}

Young Hak Kim and Michiaki Mishima

Department of Respiratory Medicine, Graduate School of Medicine, Kyoto University,

54 Shogoin-Kawaharacho, Sakyo-ku, Kyoto 606-8507, Japan

For reprints and all correspondence: Young Hak Kim

Department of Respiratory Medicine, Graduate School of Medicine, Kyoto University,

54 Shogoin-Kawaharacho, Sakyo-ku, Kyoto 606-8507, Japan

Phone: +81-75-751-3830; Fax: +81-75-751-4643; E-mail: ekim@ kuhp.kyoto-u.ac.jp

Running title: Second-line Chemotherapy for SCLC

Key words: small-cell lung cancer, relapsed, chemotherapy, second line, sensitive, refractory 


\section{Abstract}

Although small-cell lung cancer (SCLC) generally shows an excellent response to initial chemotherapy, most patients finally relapse and salvage chemotherapy is considered. Usually, the response to salvage chemotherapy significantly differs between sensitive and refractory relapse. Sensitive relapse is relatively chemosensitive and re-challenge with the same drugs as used in the initial chemotherapy has been used historically, while refractory relapse is extremely chemoresistant and its prognosis has been abysmal. To date, a number of clinical trials have been carried out for relapsed SCLC; however, the number of randomized trials is quite limited. At present, topotecan is the only drug approved by the US Food and Drug Administration for relapsed SCLC, and is considered the standard second-line chemotherapy in many countries. More recently, amrubicin has also shown more favorable antitumor activity, and is the most promising at present. Unfortunately, targeted agents have failed to demonstrate effectiveness for SCLC. Better understanding of the molecular mechanisms is clearly needed. 


\section{Introduction}

Small-cell lung cancer (SCLC) is strongly associated with tobacco smoking. In recent years, the incidence of SCLC has been gradually decreasing according to the decrease of the smoking population, and it accounts for approximately $13 \%$ of all lung cancer cases. $^{1}$

Good sensitivity to chemotherapy and radiotherapy is a feature of SCLC and most patients respond to initial chemotherapy or chemoradiotherapy; however, the majority of patients develop recurrence and the prognosis of such patients is reportedly $2-4$ months. $^{2}$

In predicting the efficacy of salvage chemotherapy, both the response and the duration of the response to initial chemotherapy are important. ${ }^{3,4}$ Based on these factors, relapsed or refractory SCLC has been classified into 2 groups: patients who respond to the initial chemotherapy and relapse more than 2 or 3 months after the completion of chemotherapy are considered to be 'sensitive relapse' patients, while patients whose tumor is stable or progresses during the initial chemotherapy or who have a recurrence within 2 or 3 months after the completion of chemotherapy are considered to be 'refractory relapse' patients. ${ }^{5}$

Previous studies have reported the effectiveness of re-challenge with the same drugs used in the initial chemotherapy and it has been justified for sensitive relapse ${ }^{5-7}$; however, refractory relapse is exceedingly chemo-resistant, and response rates of less than $10 \%$ are usually attained with single-agent chemotherapy in those patients. ${ }^{8}$ Consequently, although a number of chemotherapy regimens have been evaluated in 
clinical trials and some have shown promising antitumor activity, no standard chemotherapy had been established for relapsed SCLC until recently. Currently, topotecan is the only drug approved by the US Food and Drug Administration for relapsed SCLC, and is considered the standard second-line chemotherapy in many countries. ${ }^{9}$ More recently, amrubicin has also shown promising antitumor activity in this setting $^{10,11}$; however, to date it is not approved outside Japan.

\section{Cytotoxic agents}

\section{Single-agent chemotherapy (except for topotecan and amrubicin)}

Etoposide was composed in 1966 and has been used for the treatment of SCLC. It was initially evaluated in the second-line setting because the combination of cyclophosphamide, doxorubicin, and vincristine (CAV) was the standard first-line regimen for SCLC at the time. In the study conducted by Evans et al., 18 refractory relapse patients were treated with etoposide. Fourteen patients were evaluable for response, and only 1 partial response (PR) was observed. ${ }^{12}$ Wolff et al. evaluated the efficacy of etoposide at three different doses in relapsed SCLC: 300, 600, and 900 $\mathrm{mg} / \mathrm{m}^{2}$. Twenty-six, 27, and 26 patients were treated at each dose level; however, only 4 patients achieved PR and the response rate was $6 \% .{ }^{13}$ These results suggest that single-agent etoposide has only limited activity in the second-line setting.

Irinotecan is a hemisynthetic product of camptothecin and shows strong antitumor activity by inhibiting DNA topoisomerase I. In the first-line setting, the Japan Clinical Oncology Group (JCOG) conducted a randomized phase III study comparing cisplatin-etoposide (PE) with cisplatin-irinotecan (PI) in patients with extensive disease (ED)-SCLC and showed that PI was significantly superior to PE with regard to both 
response and survival. ${ }^{14}$ Although subsequent studies conducted in the US failed to reproduce the results of the JCOG study, the efficacy of PE and PI was almost identical and both are thought to be standard first-line regimens for ED-SCLC. ${ }^{15,16}$ In the second-line setting, Masuda et al. conducted a phase II study of irinotecan. Fifteen patients were given $100 \mathrm{mg} / \mathrm{m}^{2}$ of irinotecan every week and a response rate of $47 \%$ was observed. ${ }^{17}$ In the randomized phase II study comparing irinotecan alone with the combination of irinotecan and gemcitabine, however, no partial or complete response was observed $(n=31) .{ }^{18}$ In the study, $64 \%$ of patients had a refractory relapse. Although single-agent of irinotecan is promising in the second-line setting, its efficacy is limited for refractory relapse.

Paclitaxel promotes the assembly of tubulin into microtubules and renders the microtubule resistant to depolymerization, interfering with mitosis, and has demonstrated an antitumor effect against SCLC in both preclinical and clinical studies. $^{19,20}$ In the phase II study conducted by Smit et al., 24 heavily pretreated SCLC patients were treated with paclitaxel, $175 \mathrm{mg} / \mathrm{m}^{2}$ intravenously every 3 weeks. Of 24 patients, 15 had previously received more than 2 regimens, and a $29 \%$ response rate was achieved. ${ }^{21}$ Although it may be active against drug-resistant SCLC, there is insufficient clinical evidence to use paclitaxel routinely in the clinical setting.

Gemcitabine, a novel nucleoside analogue similar in structure to cytosine arabinoside (ara-C), is a pyrimidine antimetabolite, and its mechanism of action has been well characterized. In the phase II study conducted by Hoang et al., 27 pretreated SCLC patients were treated with $1250 \mathrm{mg} / \mathrm{m}^{2}$ of gemcitabine intravenously on days 1 and 8 , every 3 weeks. Of 27 patients, 15 were sensitive and 12 had a refractory relapse. There were no PR and only 3 patients achieved stable disease (SD). The authors 
concluded that single-agent of gemcitabine had only limited activity against previously treated SCLC. ${ }^{22}$

Pemetrexed, a multitargeted antifolate agent, has been approved for non-small-cell lung cancer (NSCLC) and malignant mesothelioma worldwide. Based on an in vitro study which showed growth inhibition of the SCLC cell line ${ }^{23}$, Jalal et al. carried out a phase II study of pemetrexed in SCLC patients. Pemetrexed was administered at $500 \mathrm{mg} / \mathrm{m}^{2}$ intravenously every 3 weeks for up to 6 cycles. Twenty sensitive relapse and 23 refractory relapse patients were enrolled; however, only 1 patient had PR and 3 had SD in each group. ${ }^{24}$ In the study conducted by Gronberg et al., high-dose pemetrexed $\left(900 \mathrm{mg} / \mathrm{m}^{2}\right)$ was given with the supplementation of vitamin B12 and folic acid. Among 34 patients who received the study treatment, only 1 patient (3\%) achieved PR and $29(85 \%)$ had progressive disease (PD). ${ }^{25}$ Pemetrexed was also investigated in the first-line setting. In the study, chemotherapy-naïve patients with ED-SCLC were randomized to receive either carboplatin-pemetrexed or carboplatin-etoposide. The response and survival of carboplatin-pemetrexed was significantly inferior to those of carboplatin-etoposide. ${ }^{26}$ Thus, further exploration of pemetrexed is not warranted in SCLC.

Picoplatin is a cisplatin analog designed to avoid the development of platinum resistance, and preclinical data demonstrated that picoplatin overcomes platinum resistance in lung cancer. Eckardt et al. conducted a phase II study of picoplatin in patients with platinum-refractory or -resistant, relapsed SCLC. Seventy-seven patients were treated with picoplatin and 72 were assessable for response. There were 3 PRs (4\%), 33 SDs (43\%), and 36 PDs $(47 \%) .{ }^{27}$ A phase III study comparing picoplatin with best supportive care (BSC) is ongoing. 
The efficacy data of single-agent chemotherapy except for topotecan and amrubicin are summarized in Table $1^{3,12,13,17,18,21,22,24,25,27-33}$

\section{Combination chemotherapy}

In the era of CAV, the most intensively investigated second-line regimen was PE. In the study conducted by Evans et al., 15 of 34 evaluable patients had PR (response rate: $44 \%) .{ }^{12}$ In their subsequent study, 78 patients were treated with PE and 43 achieved a marked response (response rate: 55\%), including 6 complete responses (CR). ${ }^{34}$ In other studies, $40 \%^{35}$ and $50 \%^{36}$ response rates were observed for PE; however, there is an issue that the percentages of sensitive and refractory relapse were not presented in those studies. In fact, only a $12 \%$ response rate was observed in the study conducted by Batist et al. $^{37}$ In the study, the median time since the last chemotherapy was 3 weeks (range, 1-24), suggesting that the majority of patients had refractory relapse. Porter et al. reported a $52 \%$ response rate for 29 refractory relapse; however, the definition of 'refractory' in the study was not clear. ${ }^{38}$ Recently, in a randomized phase II study comparing PE with the combination of cisplatin, etoposide, and carboplatin, a $19 \%$ response rate was noted for refractory relapse in the PE arm. ${ }^{39}$ The platin-etoposide combination seems active in sensitive relapse; however, its efficacy is not evident in refractory relapse.

Irinotecan has been extensively investigated in combination with both cisplatin (PI) and carboplatin (CI). Ando et al. examined weekly PI. Twenty-five patients who had previously been treated with etoposide and a platinum-containing regimen were enrolled, and 20 patients achieved PR (response rate: $80 \%) .{ }^{40}$ In this study, even among 16 refractory relapse patients, 13 PR $(81 \%)$ were observed. Naka et al. conducted a 
phase II study of weekly CI, which consisted of an area under the curve (AUC) $=2$ of carboplatin and $50 \mathrm{mg} / \mathrm{m}^{2}$ of irinotecan on days 1 , 8 , and 15 every 4 weeks. In refractory relapse, 3 of 13 patients had a PR (23.1\%), and in sensitive relapse, 6 of 16 had a PR (37.5\%), and there was no statistical significance in the response rate between the two. ${ }^{41}$ In the study conducted by Hirose et al., patients were treated with CI, AUC = 5 of carboplatin on day 1 and $50 \mathrm{mg} / \mathrm{m}^{2}$ of irinotecan on days 1 and 8 every 3 weeks. Of 22 evaluable patients, 15 achieved PR, with an overall response rate of $68 \%$. Response rates in sensitive and refractory relapse were $92 \%$ and $33 \%$, respectively. ${ }^{42}$ Masuda et al. evaluated the effectiveness of combination chemotherapy of etoposide-irinotecan. In their study, 25 patients were treated with $80 \mathrm{mg} / \mathrm{m}^{2}$ of etoposide on days 1 to 3 and 70 $\mathrm{mg} / \mathrm{m}^{2}$ of irinotecan on days 1,8 , and 15 every 4 weeks, and the response rates were $75 \%$ for refractory relapse and $70 \%$ for sensitive relapse, respectively. ${ }^{43}$ The combination of irinotecan and gemcitabine was also investigated in several studies; however, the response rates for refractory relapse were not promising. ${ }^{18,44,45}$

Three-drug combination of cisplatin, etoposide, and irinotecan (PEI) was investigated separately for both sensitive and refractory relapse. Goto et al. treated 40 sensitive relapse patients with the PEI regimen, which consisted of $25 \mathrm{mg} / \mathrm{m}^{2}$ of cisplatin weekly for 9 weeks, $25 \mathrm{mg} / \mathrm{m}^{2}$ of etoposide for 3 days in weeks $1,3,5,7$, and 9 , and $90 \mathrm{mg} / \mathrm{m}^{2}$ of irinotecan in weeks $2,4,6$, and 8 with granulocyte colony-stimulating factor support. Five CRs and 26 PRs were observed, and the overall response rate was $78 \%$. The median survival time (MST) and 1-year survival rate were 11.8 months and 49\%, respectively. ${ }^{46}$ Grade 3/4 leucocytopenia, neutropenia, and thrombocytopenia were observed in 55, 73, and $33 \%$ of the patients, respectively. Non-hematologic toxicities were mild and transient in all patients. No treatment-related 
deaths were observed. Considering that this regimen also achieved a $70 \%$ response rate in refractory relapse $\mathrm{e}^{47}$, PEI warrants further investigation in the second-line setting.

The combination of carboplatin and paclitaxel (CP) was evaluated for refractory relapse in 2 studies. In the study conducted by Groen et al., 35 refractory relapse patients who were resistant to cyclophosphamide, doxorubicin, and etoposide were treated with $\mathrm{CP}$ consisting of $175 \mathrm{mg} / \mathrm{m}^{2}$ of paclitaxel on day 1 and AUC $=7$ of carboplatin on day 1 every 3 weeks. There were 2 CRs and 23 PRs, and the overall response rate was $73 \%$. MST and the 1-year survival rate was 31 weeks and $9 \%$, respectively. ${ }^{48}$ In the other study conducted by Kakolyris et al., 22 refractory relapse patients were treated with CP consisting of $200 \mathrm{mg} / \mathrm{m}^{2}$ of paclitaxel on day 1 and AUC $=6$ of carboplatin on day 1 every 3 weeks, with a $25 \%$ response rate. $^{49}$

Table 2 shows the results of combination chemotherapy in relapsed SCLC. ${ }^{12,18,34-61}$

\section{Topotecan and Amrubicin}

Topotecan, a water-soluble, semisynthetic derivative of camptothecin, is a specific inhibitor of topoisomerase, and has been most intensively evaluated in recurrent SCLC. In the study conducted by Ardizzoni et al., 101 patients were enrolled, and 92 (45 sensitive and 47 refractory) were assessable for response. Among refractory relapse patients, there were $1 \mathrm{CR}$ and $2 \mathrm{PRs}$, with an overall response rate of $6.4 \%$, whereas in sensitive relapse, there were 6 CRs and 11 PRs, for an overall response rate of $37.8 \%$. MST of sensitive and refractory relapse patients was 6.9 months and 4.7 months, respectively. ${ }^{62}$ Combined with other studies, the overall response rate and MST of topotecan were $6.4 \%$ to $38 \%$ and 6.4 to 8.7 months in sensitive relapse, and $2.4 \%$ to 
$6.4 \%$ and 4.1 to 5.1 months in refractory relapse, respectively. ${ }^{62-66}$ The results of phase II studies of topotecan are summarized in Table $3{ }^{62-66}$

Von Pawel et al. conducted the first phase III study in patients with recurrent SCLC, in which topotecan and CAV were compared. Patients received either topotecan $\left(1.5 \mathrm{mg} / \mathrm{m}^{2}\right)$ as a 30 -minute infusion daily for 5 days every 3 weeks or CAV (cyclophosphamide $1,000 \mathrm{mg} / \mathrm{m}^{2}$, doxorubicin $45 \mathrm{mg} / \mathrm{m}^{2}$, and vincristine $2 \mathrm{mg}$ ) infused on day 1 every 3 weeks. All patients had relapsed at least 60 days after completion of first-line chemotherapy. The response rate, median time to progression (TTP), and MST were $24.3 \%, 13.3$ weeks, and 25.0 weeks in the topotecan arm and $18.3 \%, 12.3$ weeks, and 24.7 weeks in the CAV arm, respectively ( $\mathrm{p}=0.285$ for the response rate, $\mathrm{p}=0.552$ for TTP, and $\mathrm{p}=0.795$ for MST, respectively). The proportion of patients who experienced symptom improvement was greater in the topotecan arm than in the CAV arm for 4 of 8 symptoms evaluated, including dyspnea, anorexia, hoarseness, and fatigue, as well as interference with daily activity. ${ }^{67}$ The oral formulation of topotecan is similar in efficacy and tolerability to IV topotecan, and more convenient than IV topotecan. ${ }^{68,69}$ In the phase III study conducted by O'Brien et al., BSC alone and BSC+oral topotecan were compared in recurrent SCLC patients who were unsuitable for intravenous chemotherapy. In the study, 70 and 71 patients were assigned to BSC alone and topotecan group, respectively. There were $7 \% \mathrm{PR}$ and $44 \% \mathrm{SD}$ in the topotecan group, and MST almost doubled (13.9 weeks vs 25.9 weeks). ${ }^{70}$ This is the only randomized study in second-line for relapsed SCLC comparing chemotherapy with BSC. Currently, topotecan is the only drug approved by the Food and Drug Administration (FDA) for recurrent SCLC. Randomized studies of topotecan are summarized in Table $4 .^{67-70}$ 
Amrubicin is a totally synthetic 9-aminoanthracycline, (+)-(7S, 9S)-9-acetyl-9-amino-7-[(2-deoxy- $\beta$-D-erythro-pentopyranosyl)oxy]-7,8,9,10-tetrahyd ro-6,11-dihydroxy-5,12-naphthacenedione hydrochloride, with a chemical structure similar to that of doxorubicin. Amrubicin showed more potent antitumor activity than doxorubicin in several human tumor xenografts implanted in nude mice. ${ }^{71}$ Acute toxicity of amrubicin is qualitatively similar to that of doxorubicin; however, amrubicin shows almost no delayed toxicity (e.g. cardiotoxicity). ${ }^{72-74}$ Amrubicin is converted to an active metabolite, amrubicinol, by reduction of its C-13 ketone group to a hydroxyl group. In vitro cytotoxic activity of amrubicinol was almost equipotent to that of doxorubicin and is 20 to 220 times more potent than its parent compound, amrubicin. ${ }^{75}$ Despite their similarity in chemical structure, amrubicin has a different mode of action to doxorubicin. Amrubicin and its active metabolite, amrubicinol, are inhibitors of DNA topoisomerase II. In a phase I-II study of patients with non-small cell lung cancer, amrubicin was administered as a 5-min intravenous infusion for 3 consecutive days. The maximum tolerated dose (MTD) was $50 \mathrm{mg} / \mathrm{m}^{2} /$ day and the dose-limiting toxicities were leukopenia, neutropenia, thrombocytopenia, and gastrointestinal complications. The recommended dose in the phase II study was $45 \mathrm{mg} / \mathrm{m}^{2} /$ day for 3 consecutive days

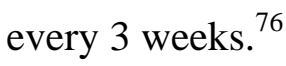

As for SCLC, Yana et al. conducted a phase II study on previously untreated ED-SCLC. Amrubicin was administered at a dose of $45 \mathrm{mg} / \mathrm{m}^{2} /$ day intravenously on days 1 to 3 , every 3 weeks. Of the 33 patients, 3 had CR and 22 had PR, with an overall response rate of $75.8 \%$. MST was 11.7 months, and 1-year and 2-year survival rates were $48.5 \%$ and $20.2 \%$, respectively; however, hematologic toxicities were severe: Grade 3/4 neutropenia, anemia, and thrombocytopenia were observed in $84.8 \%, 78.8 \%$, 
and $39.4 \% .^{77}$ For relapsed patients, a phase I study was conducted by Okamoto et al. Fifteen patients were treated with amrubicin at doses of 30,35 , or $40 \mathrm{mg} / \mathrm{m}^{2}$ on 3 consecutive days every 3 weeks. Grade 4 neutropenia was observed in $67 \%$ of patients, and the maximum tolerated dose and recommended dose were determined as $40 \mathrm{mg} / \mathrm{m}^{2}$ and $35 \mathrm{mg} / \mathrm{m}^{2}$, respectively. ${ }^{78}$ Similarly, Igawa et al. conducted a dose-escalating study of second-line and third-line settings separately. The recommended doses were determined as $40 \mathrm{mg} / \mathrm{m}^{2}$ for the second-line setting and $35 \mathrm{mg} / \mathrm{m}^{2}$ for the third-line setting, respectively. ${ }^{79}$

In Japan, 3 phase II studies have been conducted at different doses of amrubicin for relapsed SCLC. In the first study, conducted by Kato et al., $45 \mathrm{mg} / \mathrm{m}^{2}$ of amrubicin was administered on days 1-3 every 3 weeks. Thirty-four patients were treated with amrubicin, and there were 4 CRs and 14 PRs, with a response rate of $53 \%$. The response rate and MST in sensitive relapse and refractory relapse were 50\% and 10.4 months, and $60 \%$ and 6.8 months, respectively. ${ }^{80}$ In the second study, conducted by Onoda et al., $40 \mathrm{mg} / \mathrm{m}^{2}$ of amrubicin was administered on the same schedule and 60 patients were enrolled. The response rate and MST in sensitive relapse and refractory relapse were $52 \%$ and 11.6 months, and $50 \%$ and 10.3 months, respectively. ${ }^{10}$ The third study was conducted by Kaira et al. and $35 \mathrm{mg} / \mathrm{m}^{2}$ of amrubicin was administered to both SCLC and NSCLC patients. In this study, 29 relapsed SCLC patients were enrolled, and the response rate and MST in sensitive relapse and refractory relapse were $60 \%$ and 12.0 months, and $37 \%$ and 11.0 months, respectively. ${ }^{81}$ In the first study, grade 4 neutropenia was noted in $71 \%$ of patients; however, the incidence were $55 \%$ in the second study and $10 \%$ in the third study, respectively. Considering that efficacy data were almost similar, fewer doses seems to be preferable in relapsed patients, as 
indicated in previous phase I studies. Recently, the results of the first phase II study conducted outside Japan were presented. In the study, 75 Western patients with refractory relapse were treated with $40 \mathrm{mg} / \mathrm{m}^{2}$ of amrubicin on 3 consecutive days every 3 weeks. The response rate and MST were $21 \%$ and 6.0 months, respectively. ${ }^{82}$ The response rate and survival were considerably lower compared with Japanese phase II studies; however, consistent with the results of a Japanese randomized phase II studies comparing amrubicin with topotecan. ${ }^{11}$ Table 5 summarizes the phase II studies of amrubicin. $^{10,80-82}$

So far, two randomized phase II studies comparing topotecan and amrubicin have been conducted (Table 6). ${ }^{11,83}$ In the first study, conducted in Japan, 60 patients were randomly assigned to either amrubicin (40 $\mathrm{mg} / \mathrm{m}^{2}$ on days $1-3$, every 3 weeks) or topotecan $\left(1.0 \mathrm{mg} / \mathrm{m}^{2}\right.$ on days $1-5$, every 3 weeks $)$, and 59 were evaluable. In the study, 36 sensitive relapse and 23 refractory relapse patients were included. Response rates were $13 \%$ in the topotecan arm and $38 \%$ in the amrubicin arm $(\mathrm{p}=0.039)$ : in sensitive relapse, $21 \%$ for the topotecan arm and 53\% for the amrubicin arm; in refractory relapse, $0 \%$ for the topotecan arm and $17 \%$ for the amrubicin arm. Median progression-free survival times (PFSs) and MSTs were 2.2 months and 8.4 months for the topotecan arm, and 3.5 months and 8.1 months for the amrubicin arm, respectively. However, many patients in the topotecan arm subsequently received amrubicin, and multivariate analysis revealed that amrubicin had more impact on overall survival than topotecan. There was one treatment-related death resulting from neutropenic infection in the amrubicin arm. ${ }^{11}$ In the second study, conducted in the U.S., 76 sensitive relapse patients were randomly assigned to either amrubicin $\left(40 \mathrm{mg} / \mathrm{m}^{2}\right.$ on days $1-3$, every 3 weeks) or topotecan $\left(1.5 \mathrm{mg} / \mathrm{m}^{2}\right.$ on days $1-5$, every 3 weeks). The response rate was 
significantly better in the amrubicin arm $(11.5 \%$ vs $44 \%, \mathrm{p}=0.005)$. Median PFSs and MSTs were 3.3 months and 7.7 months for the topotecan arm, and 4.6 months and 9.3 months for the amrubicin arm, respectively. One patient in the topotecan arm and 4 patients in the amrubicin arm died due to neutropenic infection. ${ }^{83}$

\section{Targeted agents}

\section{Imatinib}

The c-KIT protein, also known as CD117, is a member of the type III receptor tyrosine kinase (TK) family, and previous studies have shown that $\sim 70 \%$ SCLC cells express c-kit. Imatinib is an orally available small molecule that inhibits several protein TK, including c-kit, platelet-derived growth factor receptor (PDGFR), and Bcr-Abl fusion protein, and is effective against chronic myeloid leukemia and gastrointestinal stromal tumors (GIST). Based on these facts, imatinib has been tested for relapsed SCLC in several clinical studies; ${ }^{84-86}$ however, none showed the effectiveness of imatinib. One possible explanation is that c-kit expression in SCLC is not correlated with activating mutations in c-kit exon 11, which predict the activity of imatinib in GIST. Further studies of imatinib are not warranted for SCLC. ${ }^{87}$

\section{Anti-angiogenic agents}

The microvessel count and vascular endothelial growth factor (VEGF) level were found to significantly affect survival in SCLC patients who underwent primary resection followed by adjuvant chemotherapy. ${ }^{88}$ These data prompted us to carry out a clinical study of anti-angiogenic agents for relapsed SCLC.

Bevacizumab is a recombinant, humanized monoclonal antibody against VEGF. 
Jalal et al. conducted a phase II study of the combination of paclitaxel and bevacizumab for sensitive relapse SCLC. Thirty-four patients were enrolled and preliminary results were reported in 27 patients: response rate, 11.1\%; SD, 55.5\%; PD,33.3\%; median PFS, 13 weeks; and MST, 21 weeks. ${ }^{89}$

Cediranib is a highly potent inhibitor of VEGFR-1, -2, and -3 TKs. In the phase II study conducted by Ramalingam et al., cediranib was administered at the daily oral dose of $45 \mathrm{mg}$, reduced to $30 \mathrm{mg}$ because of toxicity, to 25 SCLC patients pretreated with only 1 previous regimen. Unconfirmed PR was reported in 1 patient and SD in 9 patients, with median PFS of 8 weeks and MST of 6 months. Cediranib failed to meet the predefined target ( $20 \%$ response) to continue full accrual to the study. ${ }^{90}$

Sorafenib is a multi-kinase inhibitor affecting the pathways involved in tumor progression and angiogenesis, such as Raf-1, VEGFR-2, VEGFR-3, and PDGFR- $\beta$. Sorafenib was administered at the daily oral total dose of $800 \mathrm{mg}$ in 82 patients with SCLC who progressed after 1 platinum-based regimen and were stratified by platinum sensitivity. There were 4 PRs (3 sensitive relapse) and 25 SDs (12 sensitive relapse). Median PFS was 2 months in both groups, and MSTs were 7 months in sensitive relapse and 5 months in refractory relapse, respectively. ${ }^{91}$ Overall, anti-angiogenic agents are not promising for SCLC.

\section{Epidermal Growth Factor Receptor Inhibitors}

Gefitinib is an orally active inhibitor selective for the TK of epidermal growth factor receptor (EGFR). Although EGFR expression is usually not noted in SCLC cells, there have been 2 phase II studies of gefitinib for relapsed SCLC.

In the study conducted by Moore et al., 19 patients with SCLC pretreated with 
1 or 2 previous treatments received oral gefitinib at a daily dose of $250 \mathrm{mg}$; however, there was no complete or partial response. ${ }^{92}$ In another study conducted by Langer et al., among 29 patients, only 1 patient achieved PR and the response rate was $3 \% .{ }^{93}$ The most reliable predictive marker of response with EGFR tyrosine kinase inhibitors, including gefitinib, is somatic mutation of the EGFR gene, and the frequency of mutation is exclusively high in adenocarcinoma histology. ${ }^{94}$ Although mutation data are lacking for SCLC, further studies of EGFR inhibitors are not warranted.

\section{Farnesyl Transferase Inhibitor}

Ras is a protein requiring farnesylation before it can mediate its proliferative functions, which is critical in carcinogenic processes. Tipifarnib is an oral non-peptidomimetic farnesyl transferase inhibitor that blocks the activity of farnesylated proteins involved in the signal transduction pathways critical for cell proliferation and survival. Heymach et al. conducted a phase II study of single-agent tipifarnib. Twenty-two sensitive relapse patients were enrolled; however, no significant antitumor activity was noted. ${ }^{95}$ One possible explanation for the lack of sensitivity to tipifarnib is the absence of activating Ras mutations in SCLC cells.

\section{Conclusions}

A large number of clinical studies of relapsed SCLC have been conducted; however, treatment advances are slow. In addition, no targeted agents have proved effective, unlike in NSCLC. Better understanding of the molecular mechanisms is clearly needed, but amrubicin is the most promising at present. A Phase III study comparing amrubicin with topotecan in relapsed SCLC is underway in the EU and US. 


\section{References}

1. Govindan R, Page N, Morgensztern D et al. Changing epidemiology of small-cell lung cancer in the United States over the last 30 years: analysis of the surveillance, epidemiologic, and end results database. J Clin Oncol 2006; 24: 4539-44.

2. Postmus PE, Smit EF. Treatment of relapsed small cell lung cancer. Semin Oncol 2001; 28: 48-52.

3. Giaccone G, Donadio M, Bonardi G et al. Teniposide in the treatment of small-cell lung cancer: the influence of prior chemotherapy. J Clin Oncol 1988; 6: 1264-70.

4. Ebi N, Kubota K, Nishiwaki Y et al. Second-line chemotherapy for relapsed small cell lung cancer. Jpn J Clin Oncol 1997; 27: 166-9.

5. Rosti G, Bevilacqua G, Bidoli P et al. Small cell lung cancer. Ann Oncol 2006; 17 Suppl 2: ii5-10.

6. Giaccone G, Ferrati P, Donadio M et al. Reinduction chemotherapy in small cell lung cancer. Eur J Cancer Clin Oncol 1987; 23: 1697-9.

7. Postmus PE, Berendsen HH, van Zandwijk N et al. Retreatment with the induction regimen in small cell lung cancer relapsing after an initial response to short term chemotherapy. Eur J Cancer Clin Oncol 1987; 23: 1409-11.

8. Glisson BS. Recurrent small cell lung cancer: update. Semin Oncol 2003; 30: 72-78.

9. Ardizzoni A. Topotecan in the treatment of recurrent small cell lung cancer: an update. Oncologist 2004; 9 Suppl 6: 4-13.

10. Onoda S, Masuda N, Seto T et al. Phase II trial of amrubicin for treatment of refractory or relapsed small-cell lung cancer: Thoracic Oncology Research Group Study 0301. J Clin Oncol 2006; 24: 5448-53

11. Inoue A, Sugawara S, Yamazaki K et al. Randomized phase II trial comparing amrubicin with topotecan in patients with previously treated small-cell lung cancer: North Japan Lung Cancer Study Group Trial 0402. J Clin Oncol 2008; 26: 5401-6.

12. Evans WK, Feld R, Osoba D et al. VP-16 alone and in combination with cisplatin in previously treated patients with small cell lung cancer. Cancer 1984; 53: 1461-6.

13. Wolff SN, Birch R, Sarma P, Greco FA. Randomized dose-response evaluation of etoposide in small cell carcinoma of the lung: a Southeastern Cancer Study Group Trial. Cancer Treat Rep 1986; 70: 583-7.

14. Noda K, Nishiwaki Y, Kawahara M et al. Irinotecan plus cisplatin compared with etoposide plus cisplatin for extensive small-cell lung cancer. N Engl J Med 2002; 346: 85-91.

15. Hanna N, Bunn PA, Jr., Langer $\mathrm{C}$ et al. Randomized phase III trial comparing irinotecan/cisplatin with etoposide/cisplatin in patients with previously untreated extensive-stage disease 
small-cell lung cancer. J Clin Oncol 2006; 24: 2038-43.

16. Lara PN, Jr., Natale R, Crowley J et al. Phase III trial of irinotecan/cisplatin compared with etoposide/cisplatin in extensive-stage small-cell lung cancer: clinical and pharmacogenomic results from SWOG S0124. J Clin Oncol 2009; 27: 2530-5.

17. Masuda N, Fukuoka M, Kusunoki Y et al. CPT-11: a new derivative of camptothecin for the treatment of refractory or relapsed small-cell lung cancer. J Clin Oncol 1992; 10: 1225-9.

18. Pallis AG, Agelidou A, Agelaki S et al. A multicenter randomized phase II study of the irinotecan/gemcitabine doublet versus irinotecan monotherapy in previously treated patients with extensive stage small-cell lung cancer. Lung Cancer 2009; 65: 187-91.

19. Yamori T, Sato S, Chikazawa H, Kadota T. Anti-tumor efficacy of paclitaxel against human lung cancer xenografts. Jpn J Cancer Res 1997; 88: 1205-10.

20. Ettinger DS, Finkelstein DM, Sarma RP, Johnson DH. Phase II study of paclitaxel in patients with extensive-disease small-cell lung cancer: an Eastern Cooperative Oncology Group study. J Clin Oncol 1995; 13: 1430-5.

21. Smit EF, Fokkema E, Biesma B et al. A phase II study of paclitaxel in heavily pretreated patients with small-cell lung cancer. Br J Cancer 1998; 77: 347-51.

22. Hoang T, Kim K, Jaslowski A et al. Phase II study of second-line gemcitabine in sensitive or refractory small cell lung cancer. Lung Cancer 2003; 42: 97-102.

23. Chan DC, Chen VJ, Zhang Z et al. Studies of pemetrexed and gemcitabine, alone and in combinations, in human lung cancer models. ASCO Meeting Abstracts 2006; 24: 17114.

24. Jalal S, Ansari R, Govindan R et al. Pemetrexed in second line and beyond small cell lung cancer: a Hoosier Oncology Group phase II study. J Thorac Oncol 2009; 4: 93-6.

25. Gronberg BH, Bremnes RM, Aasebo U et al. A prospective phase II study: high-dose pemetrexed as second-line chemotherapy in small-cell lung cancer. Lung Cancer 2009; 63: 88-93.

26. Socinski MA, Smit EF, Lorigan P et al. Phase III study of pemetrexed plus carboplatin compared with etoposide plus carboplatin in chemotherapy-naive patients with extensive-stage small-cell lung cancer. J Clin Oncol 2009; 27: 4787-92.

27. Eckardt JR, Bentsion DL, Lipatov ON et al. Phase II study of picoplatin as second-line therapy for patients with small-cell lung cancer. J Clin Oncol 2009;27:2046-51.

28. Planting AS, Splinter TA, Ardizzoni A et al. Phase II study of ACNU as second-line treatment in small-cell lung cancer. EORTC Lung Cancer Cooperative Group. Cancer Chemother Pharmacol 1992; 29: 409-11.

29. Ardizzoni A, Antonelli G, Ricci S et al. Ambamustine in the second-line treatment of patients with small-cell lung cancer: a phase II Fonicap study. Am J Clin Oncol 2000; 23: 22-5.

30. Sessa C, Wanders J, Roelvink M et al. Second-line treatment of small-cell lung cancer with the camptothecin-derivative GI147211: a study of the EORTC Early Clinical Studies Group (ECSG). Ann 
Oncol 2000; 11: 207-10.

31. Samantas E, Kalofonos H, Linardou H et al. Phase II study of pegylated liposomal doxorubicin: inactive in recurrent small-cell lung cancer. A Hellenic Cooperative Oncology Group Study. Ann Oncol 2000; 11: 1395-7.

32. Schmittel A, Knodler M, Hortig $\mathrm{P}$ et al. Phase II trial of second-line bendamustine chemotherapy in relapsed small cell lung cancer patients. Lung Cancer 2007; 55: 109-13.

33. Eisen T, Thatcher N, Leyvraz S et al. Phase II study of weekly plitidepsin as second-line therapy for small cell lung cancer. Lung Cancer 2009; 64: 60-5.

34. Evans WK, Osoba D, Feld R et al. Etoposide (VP-16) and cisplatin: an effective treatment for relapse in small-cell lung cancer. J Clin Oncol 1985; 3: 65-71.

35. Figoli F, Veronesi A, Ardizzoni A et al. Cisplatin and etoposide as second-line chemotherapy in patients with small cell lung cancer. Cancer Invest 1988; 6: 1-5.

36. Masuda N, Fukuoka M, Matsui K et al. Evaluation of high-dose etoposide combined with cisplatin for treating relapsed small cell lung cancer. Cancer 1990; 65: 2635-40.

37. Batist G, Carney DN, Cowan KH et al. Etoposide (VP-16) and cisplatin in previously treated small-cell lung cancer: clinical trial and in vitro correlates. J Clin Oncol 1986; 4: 982-6.

38. Porter LL, 3rd, Johnson DH, Hainsworth JD et al. Cisplatin and etoposide combination chemotherapy for refractory small cell carcinoma of the lung. Cancer Treat Rep 1985; 69: 479-81.

39. Sculier JP, Lafitte JJ, Lecomte $\mathrm{J}$ et al. A phase II randomised trial comparing the cisplatin-etoposide combination chemotherapy with or without carboplatin as second-line therapy for small-cell lung cancer. Ann Oncol 2002; 13: 1454-9.

40. Ando M, Kobayashi K, Yoshimura A et al. Weekly administration of irinotecan (CPT-11) plus cisplatin for refractory or relapsed small cell lung cancer. Lung Cancer 2004; 44: 121-7.

41. Naka N, Kawahara M, Okishio K et al. Phase II study of weekly irinotecan and carboplatin for refractory or relapsed small-cell lung cancer. Lung Cancer 2002; 37: 319-23.

42. Hirose T, Horichi N, Ohmori T et al. Phase II study of irinotecan and carboplatin in patients with the refractory or relapsed small cell lung cancer. Lung Cancer 2003; 40: 333-8.

43. Masuda N, Matsui K, Negoro S et al. Combination of irinotecan and etoposide for treatment of refractory or relapsed small-cell lung cancer. J Clin Oncol 1998; 16: 3329-34.

44. Schuette W, Nagel S, Juergens S et al. Phase II trial of gemcitabine/irinotecan in refractory or relapsed small-cell lung cancer. Clin Lung Cancer 2005; 7: 133-7.

45. Rocha-Lima CM, Herndon JE 2nd, Lee ME et al. Phase II trial of irinotecan/gemcitabine as second-line therapy for relapsed and refractory small-cell lung cancer: Cancer and Leukemia Group B Study 39902. Ann Oncol 2007; 18: 331-7.

46. Goto K, Sekine I, Nishiwaki Y et al. Multi-institutional phase II trial of irinotecan, cisplatin, and etoposide for sensitive relapsed small-cell lung cancer. Br J Cancer 2004; 91: 659-65. 
47. Kim Y, Goto K, Nishiwaki Y et al. Phase II study of weekly cisplatin, etoposide and irinotecan (PE/CPT) for refractory relapsed small cell lung cancer (SCLC). ASCO Meeting Abstracts 2006; 24: 7088 .

48. Groen HJ, Fokkema E, Biesma B et al. Paclitaxel and carboplatin in the treatment of small-cell lung cancer patients resistant to cyclophosphamide, doxorubicin, and etoposide: a non-cross-resistant schedule. J Clin Oncol 1999; 17: 927-32.

49. Kakolyris S, Mavroudis D, Tsavaris N et al. Paclitaxel in combination with carboplatin as salvage treatment in refractory small-cell lung cancer (SCLC): a multicenter phase II study. Ann Oncol 2001; 12: 193-7.

50. Roth BJ, Johnson DH, Einhorn LH et al. Randomized study of cyclophosphamide, doxorubicin, and vincristine versus etoposide and cisplatin versus alternation of these two regimens in extensive small-cell lung cancer: a phase III trial of the Southeastern Cancer Study Group. J Clin Oncol 1992; 10: 282-91.

51. Postmus PE, Smit EF, Berendsen HH, Haaxma-Reiche H. Second-line carboplatin-based chemotherapy for small cell lung cancer: the Groningen experience. Semin Oncol 1992; 19: 17-23.

52. Postmus PE, Smit EF, Kirkpatrick A, Splinter TA. Testing the possible non-cross resistance of two equipotent combination chemotherapy regimens against small-cell lung cancer: a phase II study of the EORTC Lung Cancer Cooperative Group. Eur J Cancer 1993; 29A: 204-7.

53. Falk SJ, Maughan TS, Laurence VM et al. Phase II study of carboplatin and adriamycin as second line chemotherapy in small cell lung cancer. Clin Oncol (R Coll Radiol) 1993; 5: 85-8.

54. Faylona EA, Loehrer PJ, Ansari R et al. Phase II study of daily oral etoposide plus ifosfamide plus cisplatin for previously treated recurrent small-cell lung cancer: a Hoosier Oncology Group Trial. J Clin Oncol 1995; 13: 1209-14.

55. Kubota K, Nishiwaki Y, Kakinuma R et al. Dose-intensive weekly chemotherapy for treatment of relapsed small-cell lung cancer. J Clin Oncol 1997; 15: 292-6.

56. Ichiki M, Gohara R, Rikimaru $\mathrm{T}$ et al. Combination Chemotherapy with Irinotecan and Ifosfamide as Second-Line Treatment of Refractory or Sensitive Relapsed Small Cell Lung Cancer: A Phase II Study. Chemotherapy 2002; 49: 200-5.

57. Sonpavde G, Ansari R, Walker P et al. Phase II study of doxorubicin and paclitaxel as second-line chemotherapy of small-cell lung cancer: a Hoosier Oncology Group Trial. Am J Clin Oncol 2000; 23: 68-70.

58. Kosmas C, Tsavaris NB, Malamos NA et al. Phase II study of paclitaxel, ifosfamide, and cisplatin as second-line treatment in relapsed small-cell lung cancer. J Clin Oncol 2001; 19: 119-26.

59. Isobe K, Kobayashi K, Kosaihira S et al. Phase II study of nimustine hydrochloride (ACNU) plus paclitaxel for refractory small cell lung cancer. Lung Cancer 2009; 66: 350-4.

60. Dongiovanni V, Buffoni L, Berruti A et al. Second-line chemotherapy with weekly paclitaxel 
and gemcitabine in patients with small-cell lung cancer pretreated with platinum and etoposide: a single institution phase II trial. Cancer Chemother Pharmacol 2006; 58: 203-9.

61. Leighl NB, Goss GD, Lopez PG et al. Phase II study of pegylated liposomal doxorubicin $\mathrm{HCl}$ (Caelyx) in combination with cyclophosphamide and vincristine as second-line treatment of patients with small cell lung cancer. Lung Cancer 2006; 52: 327-32.

62. Ardizzoni A, Hansen H, Dombernowsky $\mathrm{P}$ et al. Topotecan, a new active drug in the second-line treatment of small-cell lung cancer: a phase II study in patients with refractory and sensitive disease. The European Organization for Research and Treatment of Cancer Early Clinical Studies Group and New Drug Development Office, and the Lung Cancer Cooperative Group. J Clin Oncol 1997; 15 : 2090-6.

63. Eckardt J, Gralla R, Palmer MC et al. Topotecan (T) as second-line therapy in patients (Pts) with small cell lung cancer (SCLC): a phase II study. Ann Oncol 1996; 7(suppl 5): 107.

64. Depierre A, von Pawel J, Hans K et al. Evaluation of topotecan (Hycamtin ${ }^{\mathrm{TM}}$ ) in relapsed small cell lung cancer (SCLC). A multicentre phase II study. Lung Cancer 1997; 18(suppl 1): 35.

65. Takeda K, Negoro S, Sawa T et al. A phase II study of topotecan in patients with relapsed small-cell lung cancer. Clin Lung Cancer 2003; 4: 224-8.

66. Perez-Soler R, Glisson BS, Lee JS et al. Treatment of patients with small-cell lung cancer refractory to etoposide and cisplatin with the topoisomerase I poison topotecan. J Clin Oncol 1996; 14: 2785-90.

67. von Pawel J, Schiller JH, Shepherd FA et al. Topotecan versus cyclophosphamide, doxorubicin, and vincristine for the treatment of recurrent small-cell lung cancer. J Clin Oncol 1999; 17: 658-67.

68. von Pawel J, Gatzemeier U, Pujol JL et al. Phase ii comparator study of oral versus intravenous topotecan in patients with chemosensitive small-cell lung cancer. J Clin Oncol 2001; 19: 1743-9.

69. Eckardt JR, von Pawel J, Pujol JL et al. Phase III study of oral compared with intravenous topotecan as second-line therapy in small-cell lung cancer. J Clin Oncol 2007; 25: 2086-92.

70. O'Brien ME, Ciuleanu TE, Tsekov H et al. Phase III trial comparing supportive care alone with supportive care with oral topotecan in patients with relapsed small-cell lung cancer. J Clin Oncol 2006; 24: $5441-7$.

71. Morisada S, Yanagi Y, Noguchi T et al. Antitumor activities of a novel 9-aminoanthracycline (SM-5887) against mouse experimental tumors and human tumor xenografts. Jpn J Cancer Res 1989; 80: 69-76.

72. Morisada S, Yanagi Y, Kashiwazaki Y, Fukui M. Toxicological aspects of a novel 9-aminoanthracycline, SM-5887. Jpn J Cancer Res 1989; 80: 77-82.

73. Suzuki T, Minamide S, Iwasaki $\mathrm{T}$ et al. Cardiotoxicity of a new anthracycline derivative (SM-5887) following intravenous administration to rabbits: comparative study with doxorubicin. Invest New Drugs 1997; 15: 219-25. 
74. Noda $\mathrm{T}$, Watanabe $\mathrm{T}$, Kohda $\mathrm{A}$ et al. Chronic effects of a novel synthetic anthracycline derivative (SM-5887) on normal heart and doxorubicin-induced cardiomyopathy in beagle dogs. Invest New Drugs 1998; 16: 121-8.

75. Yamaoka T, Hanada M, Ichii S et al. Cytotoxicity of amrubicin, a novel 9-aminoanthracycline, and its active metabolite amrubicinol on human tumor cells. Jpn J Cancer Res 1998; 89: 1067-73.

76. Negoro S, Fukuoka M, Nakamura S, Ikegami H, Sugiura T, Ariyoshi Y. Phase I-II study of amrubicin (SM-5887), a novel 9-aminoanthracycline, by iv administration for 3 consecutive days in patients with advanced non-small-cell lung cancer. ASCO Meeting Abstracts 1995; 14: 361.

77. Yana T, Negoro S, Takada M et al. Phase II study of amrubicin in previously untreated patients with extensive-disease small cell lung cancer: West Japan Thoracic Oncology Group (WJTOG) study. Invest New Drugs 2007; 25: 253-8.

78. Okamoto I, Hamada A, Matsunaga Y et al. Phase I and pharmacokinetic study of amrubicin, a synthetic 9-aminoanthracycline, in patients with refractory or relapsed lung cancer. Cancer Chemother Pharmacol 2006; 57: 282-8.

79. Igawa S, Yamamoto N, Ueda S et al. Evaluation of the recommended dose and efficacy of amrubicin as second- and third-line chemotherapy for small cell lung cancer. J Thorac Oncol 2007; 2: $741-4$.

80. Kato T, Nokihara H, Ohe Y et al. Phase II trial of amrubicin in patients with previously treated small cell lung cancer (SCLC). ASCO Meeting Abstracts 2006; 24: 7061.

81. Kaira K, Sunaga N, Tomizawa $\mathrm{Y}$ et al. A phase II study of amrubicin, a synthetic 9-aminoanthracycline, in patients with previously treated lung cancer. Lung Cancer 2009 (in press).

82. Ettinger DS, Jotte R, Lorigan P et al. Phase II study of amrubicin as second-line therapy in patients with platinum-refractory small-cell lung cancer. J Clin Oncol 2010; 28: 2098-603.

83. Jotte R, Conkling P, Reynolds $\mathrm{C}$ et al. Results of a randomized phase II trial of amrubicin (AMR) versus topotecan (Topo) in patients with extensive-disease small cell lung cancer (ED-SCLC) sensitive to first-line platinum-based chemotherapy. ASCO Meeting Abstracts 2009; 27: 8028.

84. Johnson BE, Fischer T, Fischer B et al. Phase II study of imatinib in patients with small cell lung cancer. Clin Cancer Res 2003; 9: 5880-87.

85. Dy GK, Miller AA, Mandrekar SJ et al. A phase II trial of imatinib (ST1571) in patients with c-kit expressing relapsed small-cell lung cancer: a CALGB and NCCTG study. Ann Oncol 2005; 16: $1811-6$.

86. Krug LM, Crapanzano JP, Azzoli CG et al. Imatinib mesylate lacks activity in small cell lung carcinoma expressing c-kit protein: a phase II clinical trial. Cancer 2005; 103: 2128-31.

87. Burger $\mathrm{H}$, den Bakker MA, Stoter $\mathrm{G}$ et al. Lack of c-kit exon 11 activating mutations in c-KIT/CD117-positive SCLC tumour specimens. Eur J Cancer 2003; 39: 793-9.

88. Lucchi M, Mussi A, Fontanini G et al. Small cell lung carcinoma (SCLC): the angiogenic 
phenomenon. Eur J Cardiothorac Surg 2002; 21: 1105-10.

89. Jalal SI, Bhatia S, Einhorn LH et al. Paclitaxel (P) plus bevacizumab (B) in patients (pts) with chemosensitive relapsed small cell lung cancer (SCLC): A safety, feasibility and efficacy trial from the Hoosier Oncology Group. ASCO Meeting Abstracts 2008; 26: 19013.

90. Ramalingam SS, Mack PC, Vokes EE et al. Cediranib (AZD2171) for the treatment of recurrent small cell lung cancer (SCLC): A California Consortium phase II study (NCI \# 7097). ASCO Meeting Abstracts 2008; 26: 8078.

91. Gitlitz BJ, Glisson BS, Moon J, Reimers H, Gandara DR. Sorafenib in patients with platinum (plat) treated extensive stage small cell lung cancer (E-SCLC): A SWOG (S0435) phase II trial. ASCO Meeting Abstracts 2008; 26: 8039.

92. Moore AM, Einhorn LH, Estes D et al. Gefitinib in patients with chemo-sensitive and chemo-refractory relapsed small cell cancers: a Hoosier Oncology Group phase II trial. Lung Cancer 2006; 52: 93-7.

93. Langer SW, Pedersen BS, Ranson M, Pappot H, Loft A, Thatcher N. PHASE II STUDY OF IRESSA (GEFITINIB) IN RELAPSED AND REFRACTORY SMALL CELL LUNG CANCER (SCLC). J Thorac Oncol 2008; 3: S55.

94. Jiang H. Overview of gefitinib in non-small cell lung cancer: an Asian perspective. Jpn J Clin Oncol 2009; 39: 137-50.

95. Heymach JV, Johnson DH, Khuri FR et al. Phase II study of the farnesyl transferase inhibitor R115777 in patients with sensitive relapse small-cell lung cancer. Ann Oncol 2004; 15: 1187-93. 
Table 1 Prospective studies of single-agent chemotherapy for relapsed SCLC

\begin{tabular}{|c|c|c|c|c|c|c|}
\hline Regimen & $\mathrm{n}^{*}$ & $\begin{array}{c}\text { refractoy pts } \\
(\%)\end{array}$ & $\begin{array}{l}\mathrm{RR} \\
(\%)\end{array}$ & $\begin{array}{c}\text { RR in refractory pts } \\
(\%)\end{array}$ & $\begin{array}{c}\text { MST } \\
\text { (months) }\end{array}$ & $\begin{array}{c}\text { MST (months) } \\
\text { sensitive/refractory }\end{array}$ \\
\hline Etoposide $^{12}$ & 14 & NA & 7 & NA & 2.0 & NA \\
\hline Etoposide $^{13}$ & 77 & NA & 6 & NA & 4.4 & NA \\
\hline Teniposide $^{3}$ & 44 & NA & 34 & NA & 6.9 & NA \\
\hline Irinotecan $^{17}$ & 15 & 7 & 47 & NA & 6.2 & NA \\
\hline Irinotecan $^{18}$ & 31 & 64 & 0 & 0 & 4.6 & $8.6 / 3.8$ \\
\hline $\mathrm{ACNU}^{28}$ & 23 & NA & 4 & NA & NA & $\mathrm{NA}$ \\
\hline Paclitaxel $^{21}$ & 24 & NA & 29 & NA & 3.3 & NA \\
\hline Ambamustine $^{29}$ & 17 & 71 & 0 & 0 & 3.9 & NA \\
\hline GI147211 ${ }^{30}$ & 62 & 45 & 17 & 10 & NA & NA \\
\hline Caelyx $^{31}$ & 14 & NA & 0 & 0 & NA & NA \\
\hline Gemcitabine $^{22}$ & 27 & 44 & 0 & 0 & 6.4 & $8.8 / 4.2$ \\
\hline Bendamustine $^{32}$ & 21 & NA & 29 & NA & 7.0 & NA \\
\hline Pemetrexed $^{24}$ & 43 & 53 & 5 & 4 & 3.5 & $4.4 / 2.7$ \\
\hline Pemetrexed $^{25}$ & 34 & 26 & 3 & 11 & 4.1 & $5.3 / 3.6$ \\
\hline Plitidepsin $^{33}$ & 20 & NA & 0 & 0 & 4.8 & NA \\
\hline Picoplatin $^{27}$ & 77 & 92 & 4 & NA & 5.2 & NA \\
\hline
\end{tabular}

*number of evaluable patients for response

pts, patients; RR, response rate; MST, median survival time; NA, not available 
Table 2 Prospective studies of combination chemotherapy for relapsed SCLC

\begin{tabular}{|c|c|c|c|c|c|c|}
\hline Regimen & $\mathrm{n}^{*}$ & $\begin{array}{c}\text { Refractory } \\
\text { pts } \\
(\%) \\
\end{array}$ & $\begin{array}{l}\mathrm{RR} \\
(\%) \\
\end{array}$ & $\begin{array}{c}\text { RR in refractory } \\
\text { pts } \\
(\%)\end{array}$ & $\begin{array}{c}\text { MST } \\
\text { (months) }\end{array}$ & $\begin{array}{c}\text { MST (months) } \\
\text { sensitive/refractory }\end{array}$ \\
\hline $\mathrm{CDDP} \mathrm{ETP}^{12}$ & 34 & NA & 44 & NA & 4.0 & NA \\
\hline CDDP+ETP ${ }^{34}$ & 78 & NA & 55 & NA & NA & NA \\
\hline $\mathrm{CDDP}^{2} \mathrm{ETP}^{35}$ & 27 & NA & 41 & NA & 6.5 & NA \\
\hline CDDP+ETP ${ }^{36}$ & 18 & NA & 50 & NA & 4.7 & NA \\
\hline $\mathrm{CDDP}_{+\mathrm{ETP}^{37}}$ & 29 & NA & 12 & NA & 3.0 & NA \\
\hline $\mathrm{CDDP}_{\mathrm{CETP}}{ }^{38}$ & 29 & 100 & 52 & 52 & NA & NA \\
\hline $\mathrm{CDDP} \mathrm{ETP}^{39}$ & 31 & 52 & 29 & 19 & 4.3 & NA \\
\hline CDDP+ETP ${ }^{50}$ & 59 & 46 & 22 & 15 & NA & NA \\
\hline $\mathrm{CBDCA}+\mathrm{VCR}^{51}$ & 22 & NA & 36 & NA & 4.2 & NA \\
\hline VIMP $^{51}$ & 19 & NA & 53 & NA & 4.7 & NA \\
\hline VIMP $^{52}$ & 25 & NA & 60 & NA & 4.4 & NA \\
\hline $\mathrm{CPA}+\mathrm{DXR}+\mathrm{ETP}^{52}$ & 43 & NA & 51 & NA & 5.1 & NA \\
\hline $\mathrm{CBDCA}+\mathrm{DXR}^{53}$ & 25 & NA & 64 & NA & 5.4 & NA \\
\hline CDDP+ETP+IFM ${ }^{54}$ & 42 & NA & 55 & NA & 6.8 & NA \\
\hline $\mathrm{CODE}^{55}$ & 17 & NA & 88 & NA & 8.2 & NA \\
\hline CDDP+CPT $-11^{40}$ & 25 & 64 & 80 & 81 & 7.9 & NA \\
\hline CBDCA+CPT-11 ${ }^{41}$ & 29 & 45 & 31 & 23 & 6.1 & $6.1 / 5.7$ \\
\hline CBDCA+CPT- $11^{42}$ & 22 & 41 & 68 & 33 & 6.5 & $8.2 / 6.5$ \\
\hline $\mathrm{ETP}+\mathrm{CPT}-11^{43}$ & 25 & 16 & 71 & 75 & 9.0 & NA \\
\hline IFM+CPT- $11^{56}$ & 34 & 29 & 53 & 33 & 7.2 & NA \\
\hline GEM+CPT- $11^{44}$ & 35 & 43 & 17 & 27 & 5.8 & $8.7 / 4.5$ \\
\hline GEM+CPT- $11^{45}$ & 71 & 50 & 21 & 11 & NA & $7.1 / 3.1$ \\
\hline GEM+CPT-11 ${ }^{18}$ & 38 & 47 & 24 & 11 & 6.8 & $8.6 / 5.7$ \\
\hline $\mathrm{DXR}^{2} \mathrm{PTX}^{57}$ & 46 & 30 & 41 & 14 & 5.8 & NA \\
\hline $\mathrm{CBDCA}+\mathrm{PTX}^{48}$ & 34 & NA & 74 & NA & 7.2 & NA \\
\hline $\mathrm{CBDCA}+\mathrm{PTX}^{49}$ & 32 & 100 & 25 & 25 & 7.0 & $-/ 7.0$ \\
\hline CDDP+PTX+IFM ${ }^{58}$ & 33 & 61 & 73 & 70 & 6.5 & NA \\
\hline CDDP+ETP+CPT- $11^{46}$ & 40 & 0 & 78 & - & 11.8 & $11.8 /-$ \\
\hline CDDP+ETP+CPT- $11^{47}$ & 30 & 100 & 70 & 70 & 7.3 & $-/ 7.3$ \\
\hline $\mathrm{ACNU}^{59}$ & 24 & 100 & 25 & 25 & 5.8 & NA \\
\hline${\mathrm{PTX}+\mathrm{GEM}^{60}}^{60}$ & 31 & 32 & 26 & 20 & 7.5 & $8.3 / 2.5$ \\
\hline Caelyx+CPA+VCR ${ }^{61}$ & 31 & 29 & 10 & NA & 6.5 & NA \\
\hline
\end{tabular}

*number of evaluable patients for response

pts, patients; RR, response rate; MST, median survival time; CDDP, cisplatin; ETP, etoposide; CBDCA, carboplatin; VCR, vincristine; VIMP, vincristine+ifosfamide+mesna+carboplatin; CPA, cyclophosphamide; DXR, doxorubicin; DXR, doxorubicin;

IFM, ifosfamide; CODE, cisplatin+vincristine+doxorubicin+etoposide; CPT-11, irinotecan; GEM, gemcitabine; PTX, paclitaxel 
Table 3 Phase II studies of single-agent topotecan for relapsed SCLC

\begin{tabular}{|c|c|c|c|c|c|}
\hline Study & Phase & Chemosensitivity & $\mathrm{n}$ & Response rate (\%) & MST (months) \\
\hline \multirow[t]{2}{*}{ Ardizzoni et al. ${ }^{62}$} & II & $\mathrm{S}$ & 45 & 37.8 & 6.9 \\
\hline & & $\mathrm{R}$ & 47 & 6.4 & 4.7 \\
\hline \multirow[t]{2}{*}{ Eckardt et al. $^{63}$} & II & $\mathrm{S}$ & 36 & 19.0 & 6.2 \\
\hline & & $\mathrm{R}$ & 38 & 3.0 & 4.8 \\
\hline \multirow[t]{2}{*}{ Depierre et al. ${ }^{64}$} & II & $\mathrm{S}$ & 57 & 14.0 & 6.0 \\
\hline & & $\mathrm{R}$ & 41 & 2.4 & 3.8 \\
\hline \multirow[t]{2}{*}{ Takeda et al. $^{65}$} & II & $\mathrm{S}$ & 50 & 26.0 & 8.7 \\
\hline & & $\mathrm{R}$ & 0 & - & - \\
\hline \multirow[t]{2}{*}{ Perez-Soler et al. ${ }^{66}$} & II & $\mathrm{S}$ & 0 & - & - \\
\hline & & $\mathrm{R}$ & 32 & 11.0 & 4.7 \\
\hline
\end{tabular}

MST, median survival time; $\mathrm{S}$, sensitive; $\mathrm{R}$, refractory 
Table 4 Randomized studies of single-agent topotecan for relapsed SCLC

\begin{tabular}{|c|c|c|c|c|c|}
\hline Study & Phase & Regimen & n & Response rate (\%) & MST (weeks) \\
\hline von Pawel et al. $^{68}$ & II & Oral topotecan & 52 & 23.0 & 32.0 \\
\hline & & IV topotecan & 54 & 15.0 & 25.0 \\
\hline Eckardt et al. $^{69}$ & III & Oral topotecan & 153 & 18.3 & 33.0 \\
\hline & & IV topotecan & 151 & 21.9 & -13.0 \\
\hline O'Brien et al. $^{70}$ & III & BSC & 67 & 7.0 & 25.9 \\
\hline & & topotecan & 70 & 18.3 & 24.7 \\
\hline von Pawel et al. $^{67}$ & III & CAV & 104 & 24.3 & 25.0 \\
\hline & & topotecan & 107 & \\
\hline
\end{tabular}

MST, median survival time 
Table 5 Phase II studies of single-agent amrubicin for relapsed SCLC

\begin{tabular}{|c|c|c|c|c|c|c|}
\hline Study & Phase & Dose $\left(\mathrm{mg} / \mathrm{m}^{2}\right)$ & Chemosensitivity & $\mathrm{n}$ & Response rate (\%) & MST (months) \\
\hline Kato et al. $^{80}$ & II & 45 & $\mathrm{~S}$ & 24 & 50.0 & 10.4 \\
\hline & & & $\mathrm{R}$ & 10 & 60.0 & 6.8 \\
\hline Onoda et al. $^{10}$ & II & 40 & $\mathrm{~S}$ & 44 & 52.0 & 11.6 \\
\hline & & & $\mathrm{R}$ & 16 & 50.0 & 10.3 \\
\hline Kaira et al. $^{81}$ & II & 35 & $\mathrm{~S}$ & 10 & 60.0 & 12.0 \\
\hline & & & $\mathrm{R}$ & 19 & 36.8 & 11.0 \\
\hline Ettinger et al. $^{82}$ & II & 40 & $\mathrm{~S}$ & 0 & - & - \\
\hline & & & $\mathrm{R}$ & 75 & 21.0 & 6.0 \\
\hline
\end{tabular}

MST, median survival time; $\mathrm{S}$, sensitive; $\mathrm{R}$, refractory 
Table 6 Randomized phase II studies comparing topotecan and amrubicin for relapsed SCLC

\begin{tabular}{|c|c|c|c|c|c|c|}
\hline Study & Regimen & Chemosensitivity & $\mathrm{n}$ & $\begin{array}{c}\text { Response rate } \\
(\%)\end{array}$ & $\begin{array}{l}\text { Median PFS, } \\
\text { (months) }\end{array}$ & $\begin{array}{c}\text { Median OS, } \\
\text { (months) }\end{array}$ \\
\hline \multirow{2}{*}{ Inoue et al. $^{11}$} & & $\mathrm{R}$ & 11 & 0.0 & 1.5 & 5.4 \\
\hline & & $\mathrm{R}$ & 12 & 17.0 & 2.6 & 5.3 \\
\hline \multirow[t]{2}{*}{ Jotte et al. $^{83}$} & topotecan & $\mathrm{S}$ & 26 & 11.5 & 3.3 & 7.7 \\
\hline & & $\mathrm{R}$ & - & - & - & - \\
\hline
\end{tabular}

PFS, progression-free survival; OS, overall survival; $S$, sensitive; $R$, refractory 